\title{
An unusual case of Hughes-Stovin syndrome
}

\author{
S. Herb*, M. Hetzel*, J. Hetzel*, J. Friedrich**, J. Weber*
}

An unusual case of Hughes-Stovin Syndrome. S. Herb, M. Hetzel, J. Hetzel, J. Friedrich, J. Weber. (OERS Journals Ltd 1998.

ABSTRACT: In 1959 Hughes and STovin described a syndrome consisting of multiple pulmonary aneurysms and peripheral venous thrombosis. Since that time several cases of the Hughes-Stovin syndrome have been published.

We present the case of a $25 \mathrm{yr}$ old man who, in addition to the classical symptoms, had multiple aneurysms of the bronchial arteries, which were the cause of severe haemoptysis. An aneurysm of the left hepatic artery was also detected.

To our knowledge this is the first description of aneurysms of the bronchial arteries in Hughes-Stovin syndrome. Bleeding was successfully treated by double embolization of bronchial arteries via transfemoral catheter.

Eur Respir J 1998; 11: 1191-1193.

Hughes-Stovin syndrome is a rare condition first described in 1959 [1] and is characterized by multiple pulmonary aneurysms and peripheral venous thrombosis. Typical symptoms are recurrent fever, chills, haemoptysis and coughs. The natural course of the illness is usually fatal because of fulminant haemoptysis. The aetiology of Hughes-Stovin syndrome is still unknown.

\section{Case report}

A $25 \mathrm{yr}$ old white male was admitted to our hospital in October 1994 because of severe haemoptysis of about 500 $\mathrm{mL}$ one week prior to and of about $300 \mathrm{~mL}$ on the day of admission.

He had had fever, swelling of both legs and haemoptysis for the first time in 1985. Since then fever and haemoptysis had recurred several times. A connective tissue disease with involvement of the lung was suspected and he was treated with steroids between 1985 and 1988. In 1990 angiography demonstrated post-thrombotic alterations of both pelvic veins and the inferior vena cava and bilateral multiple pulmonary aneurysms. The diagnosis of HughesStovin syndrome was made [2].

On admission physical examination was normal, apart from varicose veins of the left thigh and calf. The chest radiograph was normal. Erythrocyte sedimentation rate was $20 \mathrm{~mm} \cdot \mathrm{h}^{-1}$. Full blood count showed mild normocytic anaemia (haemoglobin $128 \mathrm{~g} \cdot \mathrm{L}^{-1}$, haematocrit $39 \%$, white cell count $6,200 \cdot 10^{9} \cdot \mathrm{L}^{-1}$, platelet count $\left.350 \cdot 10^{9} \cdot \mathrm{L}^{-1}\right)$. Coagulation studies were normal (prothrombin time (PT) 12 $\mathrm{s}$, partial thromboplastin time (PTT) $34 \mathrm{~s}$, antithrombin III $94 \%$, protein $\mathrm{C}$ activity $82 \%$, protein $\mathrm{S}$ activity $87 \%$, activated protein $\mathrm{C}$ resistance (APCR) ratio 2.69). The haemagglutination test for Treponema pallidum, and tests for human immunodeficiency virus 1 and 2, hepatitis B surface antigen, rheumatoid factor, antinuclear antibodies, antidouble stranded DNA antibodies and antineutrophilic cytoplasmic autoantibodies were all negative.

Fibre bronchoscopy was performed and showed an exophytic pulsatile tumour with white fibrinoid onlayers in
*Dept of Internal Medicine II, and **Dept of Radiology I, University of Ulm, Germany

Correspondence: S. Herb, Dept of Interna Medicine II, University of Ulm, RobertKoch-Str. 8, 89081 Ulm, Germany, Fax: 49 7315024442

Keywords: Aneurysms of the bronchial arteries, aneurysms of the pulmonary arteries, haemoptysis, Hughes-Stovin syndrome

Received: March 261997

Accepted after revision: August 311997 the right third segment bronchus and an ectatic vessel at the posterior wall of the bronchus of the right inferior lobe. Angiographically multiple occluded pulmonary arteries were demonstrated bilaterally, some of them with aneurysmatic enlargement of up to $1 \mathrm{~cm}$ (fig. 1). Additionally a selective angiography disclosed angiodysplastically altered and dilated bronchial arteries bilaterally most pronounced in the right anterior upper lobe and a cork screw convolute in the right lower lobe (fig. 2a). During the examination the patient had severe haemoptysis again. In spite of immediately performed bronchoscopy, the origin of the bleeding could not be localized because it had stopped spontaneously. The branch of the right bronchial artery supplying the third segment was embolized with ethibloc. The following day the patient was bleeding again. Therefore the bronchial arteries of the right inferior lobe were also embolized (fig. 2b). After that, haemopty-

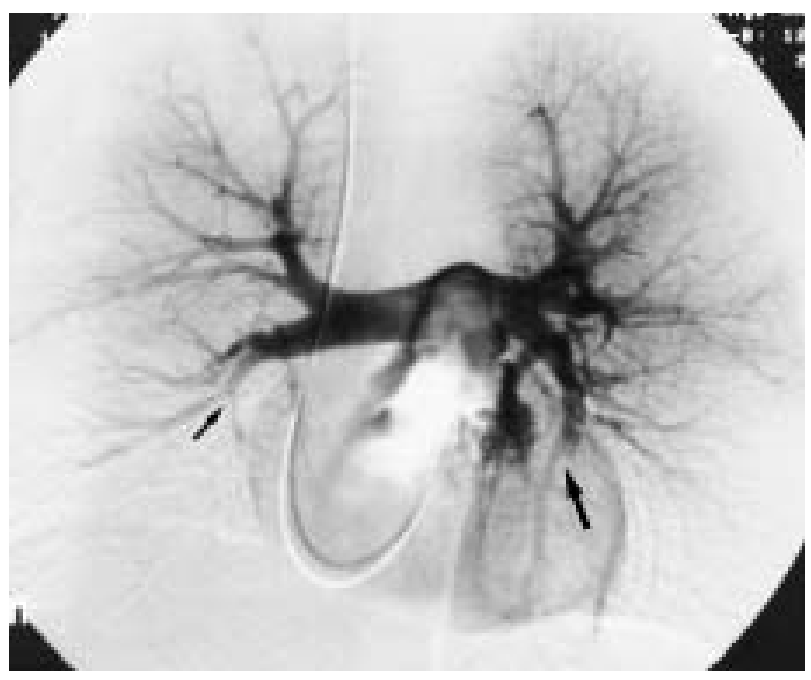

Fig. 1. - Digital subtraction angiography of the pulmonary arteries showing multiple saccular aneurysms, variations of diameter and occlusions of segmentary arteries (arrows). 


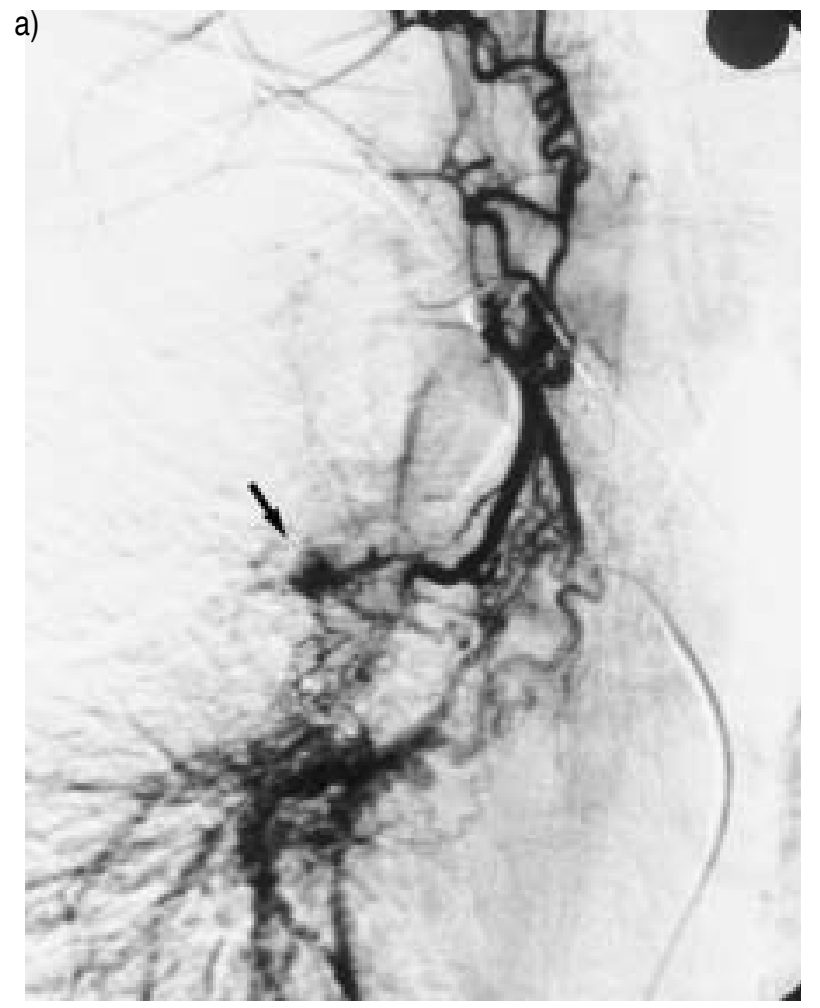

b)

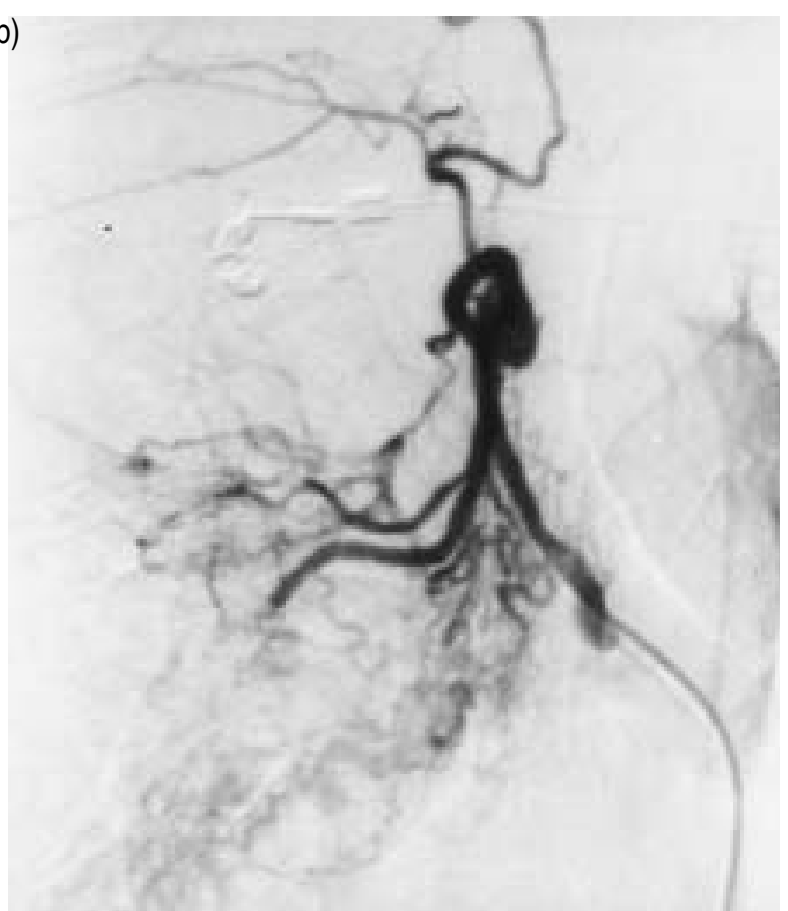

Fig. 2. - Digital subtraction angiography of the right bronchial arteries: a) before embolization showing the aneurysm of the branch supplying the right third segment (arrow) and the cork screw convolute in the right lower lobe with drainage of the blood via the pulmonary arteries and veins. b) after embolization of the arteries of the right third segment and of the right lower lobe.

sis did not recur for one and a half years. Furthermore, an angiography of the thoracic aorta showed an aneurysm of the left hepatic artery (fig. 3).

In March 1996 the patient was readmitted because he had haemoptysis of about $300 \mathrm{~mL}$. Selective angiography

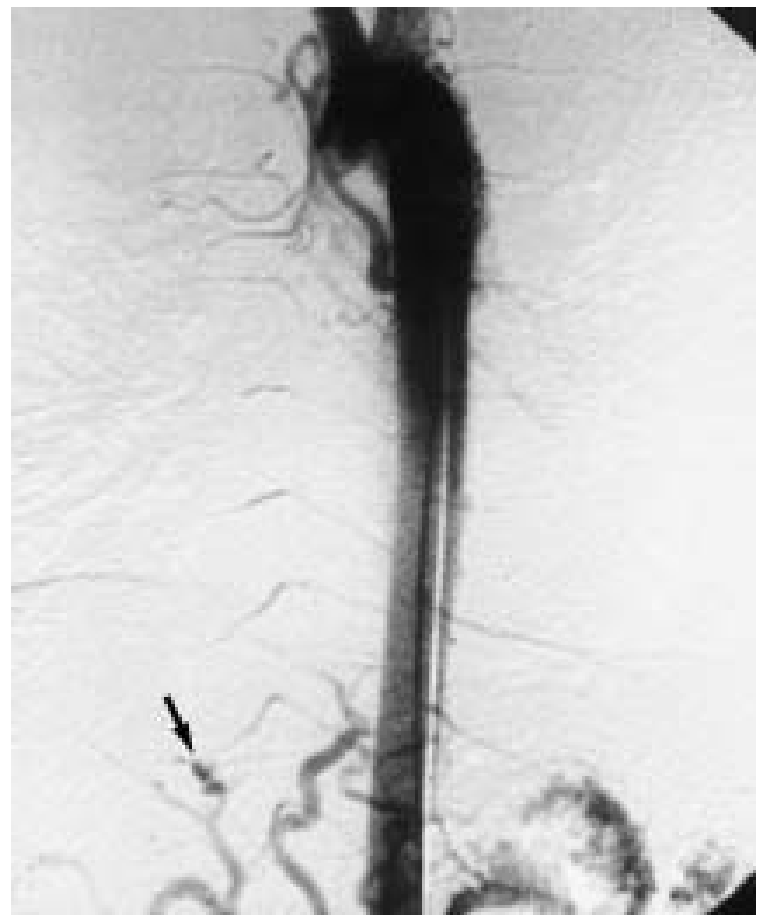

Fig. 3. - Digital subtraction angiography of the thoracic aorta showing the aneurysm of the left hepatic artery (arrow).

showed recanalization of the former embolized bronchial artery of the right third segment and was followed by embolization of the bronchial artery supplying the right upper lobe. No bleeding has recurred since then.

\section{Discussion}

In the literature, aneurysms of systemic arteries were described for a patient with Hughes-Stovin syndrome only once. KIRK and SEAL [3] described a patient who had, in addition to the classical symptoms - venous thrombosis and aneurysms of the pulmonary arteries - an aneurysm of the right external carotid artery. Our patient had bilateral aneurysms of the bronchial arteries and an aneurysm of the left hepatic artery.

To our knowledge a selective angiography of the bronchial arteries of a patient with Hughes-Stovin syndrome has not been performed previously. Whether aneurysms of the bronchial arteries were the cause of severe or even fatal haemoptysis in other patients with Hughes-Stovin syndrome remains unknown.

The pathological studies of Hughes and Stovin [1] showed evidence of a qualitative defect of the bronchial arteries, namely mineral impregnation of the elastica in-terna and fibrous tissue replacement of the muscle and elastic coats. Aneurysms were not seen. Whether there was a similar defect of the pulmonary arteries or whether the loss of elastic tissue in these vessels was a conse- quence of the organization of the embolus could not be clarified by the authors. Hughes and STovin hypothesized that the structural changes of the bronchial arteries were the cause of inadequate nutrition of the pulmonary arteries via the vasa vasorum. In consequence, the organization of an embolus was different from that in a normal pulmonary artery. Instead cellular inflammatory infiltration, destruction of the elastic tissue and formation of an aneurysm arise. 
The existence of aneurysms of pulmonary and systemic arteries is also compatible with a systemic disease. Nonetheless, coagulation studies, examination of rheumatoid and antinuclear factors and serological tests for syphilis were repeatedly normal $[1,2,4-6]$ as was the case in the present patient. Aneurysms are not described in patients with pulmonary vasculitis.

There are similarities between Hughes-Stovin syndrome and Behçet's disease [7, 8]. The angiographic and histological findings were comparable. In addition to venous thrombosis, aneurysms of the pulmonary arteries are described in patients with Behçet's disease. Both diseases are characterized by destruction of the wall of the pulmonary arteries and perivascular infiltration [7]. However, typical symptoms of Behçet's disease such as oral or genital ulcerations, skin lesions, iritis or arthralgia are missing in most of the patients with Hughes-Stovin syndrome.

Some authors described septic embolisms and abscesses as the cause of aneurysms of the pulmonary arteries [5, 9-11]. Venous thrombosis can be either the origin of the septic emboli or caused by bacterial toxins or hyperergic reactions [12].

In several cases of Hughes-Stovin syndrome infections preceded pulmonary aneurysms [5, 12-14]. Two patients had scrotal abscesses [5, 12], one suffered from epididymitis [14], and another from oophoritis [13]. However, in all cases of patients with Hughes-Stovin syndrome, in whom blood cultures were analysed, these were negative $[1,3,5,10,12-14]$.

How can the bronchial artery aneurysms be explained? One explanation for the aneurysms could be an increased blood flow and pressure in the bronchial arteries which would normally shunt blood to the now occluded pulmonary arteries. Another hypothesis is angioneogenesis due to perivascular inflammation after septic embolization of the segmental pulmonary arteries.

There is no standard therapy for Hughes-Stovin syndrome. Because so few cases were reported no controlled trials have been performed. A treatment of Hughes-Stovin syndrome similar to Behçet's disease therapy, with steroids alone or in combination with immunosuppressants, has been suggested [4]. The effectiveness is doubted because of the fatal course of most cases in spite of treatment.

There is also no clear effect of antibiotics [1, 3, 5, 14]. Anticoagulants and platelet inhibitors to prevent further thromboembolic events should not be used because of the increased risk of fatal haemoptysis [4].

If pulmonary aneurysms are limited to one segment or one lung, lobectomy or pneumectomy is principally indicated to remove the aneurysms. Durieux [7] reported three cases of Behçet's disease and Hughes-Stovin syndrome in whom singular aneurysms were surgically removed. All stayed in remission. But when the diagnosis is made, most of the patients already have involvement of both lungs [1, $3,6,14]$. The same was true in our patient [2].

In our patient haemoptysis was definitely caused by the aneurysms of the bronchial arteries. After embolization of the bronchial arteries of the third segment and the right lower lobe, bleeding stopped. Treatment of severe or recurrent haemoptysis due to lesions of the bronchial arteries by embolization of the latter is well established [15, 16]. Apart from ethibloc, other synthetic particles and coils are used. Complications are arteriovenous fistulae, abscesses, lung infarctions, bronchial necrosis, oesophageal necrosis, and spinal ischaemia. None of these occured in our patient. Recanalization or revascularization of the lesion of the bronchial artery via small previously insignificant arteries can occur, which was the reason for repeated haemoptysis in our patient. The bronchial arteries of the right upper lobe had to be embolized once again.

In conclusion, fulminant haemoptysis in patients with Hughes-Stovin syndrome can be caused by aneurysms of the bronchial arteries as well as of the pulmonary arteries. For that reason bronchial arteriography should be performed in each patient suspected of having Hughes-Stovin syndrome.

\section{References}

1. Hughes JP, Stovin PGJ. Segmental pulmonary artery aneurysm with peripheral venous thrombosis. $\mathrm{Br} J$ Dis Chest 1959; 53: 19-27.

2. Ammann ME, Karnel F, Olbert F. Radiologic findings in the diagnosis of Hughes-Stovin Syndrome. Am J Radiol 1991; 157: 1353-1354.

3. Kirk GM, Seal ME. False aneurysm of the pulmonary artery with peripheral venous thrombosis. Thorax 1964; 19: 449-453.

4. Bowman S, Honey M. Pulmonary arterial occlusions and aneurysms: a forme fruste of Behçet's or Hughes-Stovin syndrome. Br Heart J 1990; 63: 66-68.

5. Charlton RW, Du Plessis LA. Multiple pulmonary artery aneurysms. Thorax 1961; 16: 364-371.

6. Frater RWM, Beck W, Schrire V. Syndrome of pulmonary artery aneurysms, pulmonary artery thrombi and peripheral venous thrombi. J Thorac Cardiovasc Surg 1965; 49: 330-338.

7. Durieux P, Bletry O, Huchon G, Wechsler B, Chretien J, Godeau P. Multiple pulmonary arterial aneurysms in Behçet's disease and Hughes-Stovin syndrome. Am J Med 1981; 71: 736-741.

8. Francois MF. Is Hughes-Stovin syndrome a particular expression of Behçet's disease? Chest 1983; 83: 288.

9. Breeze RG, Pirie HM, Selman IE, Wiseman A. Pulmonary arterial thrombo-embolism and pulmonary arterial mycotic aneurysms in cattle with vena caval thrombosis: a condition resembling the Hughes-Stovin syndrome. $J$ Pathol 1976; 119: 229-237.

10. Calenoff L. Multiple mycotic pulmonary artery aneurysms. Am J Radiol 1964; 91: 379-384.

11. Kauffman SL, Lynfield J, Hennigar GR. Mycotic aneurysms of the intrapulmonary arteries. Circulation 1967; 35: 90-99.

12. Reimold WV, Emmrich J, Harmjanz D, Kochsiek K. Aneurysmen der Arteria pulmonalis infolge rezidivierender septischer Embolien (Hughes-Stovin-Syndrom). Arch Klin Med 1968; 215: 1-18

13. Castleman B, Bland EF. Organized emboli of the tertiary pulmonary arteries. Unusual case of cor pulmonale. Arch Path 1946; 42: 581.

14. Kopp WL, Green RA. Pulmonary artery aneurysms with recurrent thrombophlebitis: "Hughes-Stovin-syndrome." Ann Int Med 1962; 56: 105-114.

15. Remy J, Arnaud A, Fardou H: Treatment of hemoptysis by embolization of bronchial arteries. Radiology 1977; 122: 33-37.

16. Uflaker R, Kaemmerer A, Picon PD, Rizzon CFC, Neves CMC, Oliveira ESB, Azevedo SNB, Ossanai R. Bronchial artery embolization in the management of hemoptysis: technical aspects and long-term results. Radiology 157,1985: 637-644. 